\title{
A Novel Fishbone-Like Lead(II) Supramolecular Polymer: Synthesis, Characterization, and Application for Producing Nano Metal Oxide
}

\author{
Younes Hanifehpour ${ }^{1, *(\mathbb{D}}$, Babak Mirtamizdoust ${ }^{2}$, Sang Woo Joo ${ }^{3, *}$, Majid Sadeghi-Roodsari ${ }^{2}$ and $^{2}$ \\ Mehdi Abdolmaleki ${ }^{1}$
}

1 Department of Chemistry, Faculty of Science, Sayyed Jamaleddin Asadabadi University, Asadabad 6541861841, Iran; m.abdolmaleki@sjau.ac.ir

2 Department of Chemistry, Faculty of Basic Sciences, University of Qom, P.O. Box 37185-359, Qom, Iran; babakm.tamizdous @gmail.com (B.M.); chemmj94@gmail.com (M.S.-R.)

3 School of Mechanical Engineering, WCU Nano Research Center, Yeungnam University, Gyeongsan 712-749, Korea

* Correspondence: Hanifehpour@sjau.ac.ir (Y.H.); swjoo@yu.ac.kr (S.W.J.)

\section{check for}

updates

Citation: Hanifehpour, Y.; Mirtamizdoust, B.; Joo, S.W.; Sadeghi-Roodsari, M.; Abdolmaleki, M. A Novel Fishbone-Like Lead(II) Supramolecular Polymer: Synthesis, Characterization, and Application for Producing Nano Metal Oxide. Crystals 2021, 11, 335. https:// doi.org/10.3390/cryst11040335

Academic Editor: Alexander S. Novikov

Received: 1 March 2021

Accepted: 24 March 2021

Published: 26 March 2021

Publisher's Note: MDPI stays neutral with regard to jurisdictional claims in published maps and institutional affiliations.

Copyright: (c) 2021 by the authors. Licensee MDPI, Basel, Switzerland. This article is an open access article distributed under the terms and conditions of the Creative Commons Attribution (CC BY) license (https:/ / creativecommons.org/licenses/by/ $4.0 /)$.

\begin{abstract}
The nanorods of $\left[\mathrm{Pb}(\mathrm{L}) \mathrm{Br}_{2}\right]_{\mathrm{n}}(\mathbf{1})(\mathrm{L}=1$,2-bis (pyridin-3-ylmethylene)hydrazine) underwent ultrasound irradiation and were synthesized as a novel three-dimensional fishbone-like $\mathrm{Pb}$ (II)organic coordination supramolecular compound. The morphology and nanostructure of the synthesized compound were determined through SEM, FTIR, elemental analyses, and XRD. Compound 1 was structurally characterized by single-crystal X-ray diffraction and revealed six-coordinated $\mathrm{Pb}$ (II) ions bonded to two $\mathrm{N}$ atoms from two L ligands and four bromine anions, forming a onedimensional fishbone-like coordination polymer, which extended into a 3D supramolecular structure through weak intermolecular interactions. The bulk thermal stability of compound $\mathbf{1}$ was examined using thermogravimetric analysis (TGA). Moreover, $\mathrm{PbO}$ nanoparticles with sizes of $40-80 \mathrm{~nm}$ were obtained through the thermolysis of 1 at $180^{\circ} \mathrm{C}$ using oleic acid as a surfactant.
\end{abstract}

Keywords: nanorods; $\mathrm{Pb}(\mathrm{II})$; ultrasonic irradiation; nano metal oxide; crystal structure

\section{Introduction}

Coordination compounds or metal-organic hybrid materials have remarkably attracted huge attention during the past twenty years. Inorganic-organic hybrid supramolecular materials include the self-assembly of an organic ligand with proper metal ions and functional groups with special directionality and functionality [1-5]. Structural blocks are created based on coordinating interactions and other poor non-covalent inter-molecular forces, including hydrogen bonds and pi stacking, which have key roles in their stability. The attraction to these compounds comes from the effects of basic structural chemistry, and their probable applications in areas including luminescence, catalysis, nonlinear optics, magnetism and molecular sensing and adsorption, which do not exist for mononuclear compounds [6-8]. Lowering the size of nano-scaled coordination supramolecular compounds increases the surface area. Preparing any types of nano-scaled coordination supramolecular compounds is therefore the main path toward the technological application of these novel materials [9].

$\mathrm{Pb}$ (II) frameworks have attracted interest because of their large ion radius, variable coordination number, and possible occurrence of a stereochemically active lone pair of $6 s^{2}$ outer electrons with a novel network of topologies and interesting properties [10-12]. According to the hard-soft acid-base theory, the intermediate coordination ability of $\mathrm{Pb}(\mathrm{II})$ means that it can flexibly coordinate small nitrogen or oxygen atoms as well as large sulfur atoms [13]. Investigation of the stereo-chemical activity of valence shell lone electron pairs in the polymeric and supramolecular compounds may be more interesting. The 
spontaneous aggregation of several bridging ligands causes the gap to disappear, and the coordination of $\mathrm{Pb}$ (II) assumes a less common holodirected arrangement [14].

The present study introduces an eco-friendly and simple nanocrystal synthesis of a three-dimensional coordination supramolecular compound via ultrasonic irradiation. Organic synthesis was performed, and nanomaterials prepared using sonochemical techniques [15]. Further studies are still required for clarifying the application of the Ultrasound technique (UST) to constructing coordination supramolecular compounds. The present study investigated the fast synthesis of $\left[\mathrm{Pb}(\mathrm{L}) \mathrm{Br}_{2}\right]_{\mathrm{n}}(\mathbf{1})[\mathrm{L}=1,2$-bis (pyridin-3ylmethylene)hydrazine] as the nanocrystals of a one-dimensional fishbone-like $\mathrm{Pb}$ (II) coordination polymer. According to the findings obtained, Ultrasound technique (UST) synthesis is an efficient, low cost, simple and eco-friendly method for coordination supramolecular nanocompounds compared to conventional synthetic methods such as the solvent diffusion method and solvothermal and hydrothermal approaches [16].

Ultrasound technique (UST) leads to high-energy chemistry by processing acoustic cavitation, including bubbles, expansion, and their implosive collapse within a liquid intermediate [17]. UST results in alternative compressive and expansive acoustic waves to make and oscillate bubbles by irradiating liquids. Bubble can invade and consequently collapse fast, i.e., with cooling and heating rates of over $10^{10} \mathrm{Ks}^{-1}$. The huge energy concentration obtained over the collapse leads to a pressure of about one thousand bar and a local temperature of approximately $5000 \mathrm{~K}$. The energy distribution to the surroundings during collapse and after bounce causes the hot spot gas temperature to swiftly reach the temperature of the surrounding area $[18,19]$. Ultrasonic irradiation can therefore be used to assist various chemical reactions progress at room temperature, and even certain reactions formerly difficult to actualize using conventional approaches [20-23]. The present study employed oleic acid as a surfactant and performed thermolysis of 1 at $180{ }^{\circ} \mathrm{C}$ to synthesize and structurally characterize a novel nano lead(II) metal-organic supramolecular compound with 1,2-bis (pyridine-3-ylmethylene)hydrazine ligand (Scheme 1) and simply synthesize $\mathrm{PbO}$ nanoparticles.

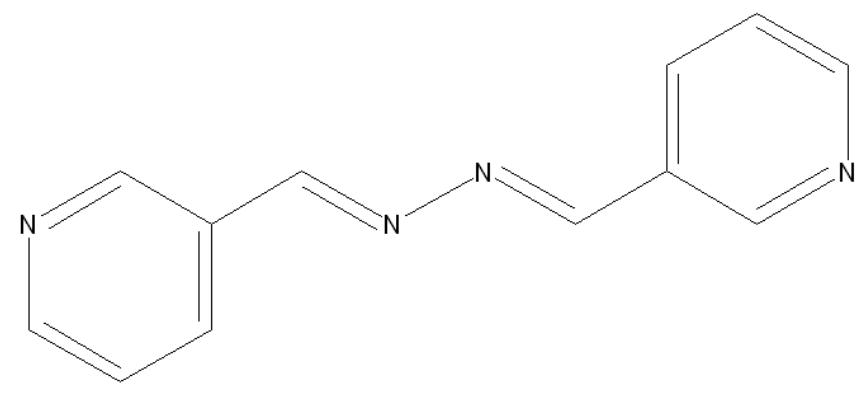

Scheme 1. 1,2-bis (pyridine-3-ylmethylene)hydrazine ligand.

\section{Experiments}

\subsection{Measurements and Materials}

Chemicals were obtained from Sigma-Aldrich (Seoul, South Korea) and used as received without further purification. Elemental analyses of the samples were carried out using a Vario Microanalyzer. FTIR was carried out by employing Bruker Vector 22 and $\mathrm{KBr}$ disks at $4000-400 \mathrm{~cm}^{-1}$. Thermogravimetric analysis (TGA) was conducted under argon flow at 20-600 degrees Celsius and a heating rate of $3{ }^{\circ} \mathrm{C} / \mathrm{min}$ using LABSYS evo (SETARAM).

X-ray powder diffraction (XRD) measurements were carried out using an X'pert diffractometer (Panalytical) with monochromatized $\mathrm{Cu}-\mathrm{K} \alpha$ radiation. In addition, $\mathrm{XRD}$ patterns were simulated in Mercury to acquire single-crystal information [24]. The morphology of the nanostructured compound was determined by scanning electron microscopy (SEM) (S-4200, Hitachi, Japan) and TEM (JEM-2200FS, JEOL). A 40 kHz Sonicator_3000 multiwave ultrasonic generator made by Misonix Inc. in the UST equipped with a titanium 
oscillator (horn) and a converter/transducer $12.5 \mathrm{~mm}$ in diameter was utilized to perform ultrasound. The minimum power output of the generator was $600 \mathrm{~W}$ for one hour at ambient temperature. The chemical composition and status of the product were evaluated by X-ray photoelectron spectroscopy (XPS) (K-ALPHA, UK).

\subsection{Preparation of 1,2-bis (pyridine-3-ylmethylene)hydrazine $(\boldsymbol{L})$}

A mixture of $5 \mathrm{mmol}(0.45 \mathrm{~mL}, 0.45 \mathrm{~g})$ of hydrazine hydrate (35 wt.\% in water) and a solution of $10 \mathrm{mmol}(1.07 \mathrm{~g})$ of nicotinaldehyde in $100 \mathrm{~mL}$ of methanol was refluxed for one day. Afterwards, the obtained yellow solids were filtered and then rinsed in methanol and dried in a vacuum (yield: $65 \%, 0.98 \mathrm{~g})$, m.p. $140{ }^{\circ} \mathrm{C}, \mathrm{FTIR}(\mathrm{KBr})=v_{\max }(698,706,817$, $863,1021,1089,1185,1225,1304,1417,1482,1586,1625,2929) \mathrm{cm}^{-1}$. H NMR (CDCl $\left.3, \mathrm{ppm}\right)$ : $8.66(\mathrm{~s}, 2 \mathrm{H}), 8.70(\mathrm{~d}, 2 \mathrm{H}), 8.97(\mathrm{~s}, 2 \mathrm{H}), 7.41(\mathrm{~d}, 2 \mathrm{H}), 8.22(\mathrm{~d}, 2 \mathrm{H})$.

\subsection{Preparation of Nanostructure and Single Crystal $\left[\mathrm{Pb}\left(\mathrm{L} \mathrm{Br}_{2}\right]_{n}(\mathbf{1})\right.$}

A total of $30 \mathrm{~mL}$ of a $0.1 \mathrm{M}$ solution of $\mathrm{PbBr}_{2}$ was added to $30 \mathrm{~mL}$ of a $0.1 \mathrm{M}$ solution of the $(L)$ ligand, and sonication performed with a high-density $40 \mathrm{kHz}, 600 \mathrm{~W}$ UST probe to make the nanostructured $\left[\mathrm{Pb}(\mathrm{L}) \mathrm{Br}_{2}\right]_{\mathrm{n}}(\mathbf{1})$. The obtained precipitate was filtered and rinsed in water and then dried in the air at the decomposition point: $330{ }^{\circ} \mathrm{C}$. According to the analyses, C: $25.0 \%, \mathrm{H}: 2.0 \%$ and $\mathrm{N}: 10.0 \%$ and $\mathrm{C}: 24.9 \%, \mathrm{H}: 1.5 \%$ and $\mathrm{N}: 9.7 \%$ were obtained for $\mathrm{C}_{12} \mathrm{H}_{10} \mathrm{Br}_{2} \mathrm{~N}_{4} \mathrm{~Pb}$. The selected FTIR bands $\left(\mathrm{cm}^{-1}\right)$ were as follows: $635 \mathrm{~s}, 750 \mathrm{~s}, 864 \mathrm{~m}$, $1045 m, 1418 s, 1482 m, 1590 s, 1620 s, 3020 w$.

An appropriate single crystal of $\left[\mathrm{Pb}(\mathrm{L}) \mathrm{Br}_{2}\right]_{\mathrm{n}}(\mathbf{1})$ determining the X-ray structure was made and isolated by inserting $1 \mathrm{mmol}$ of $L$ into an arm of a tube with branches and $1 \mathrm{mmol}$ of $\mathrm{PbBr}_{2}$ to the other arm [25]. Having filled both the arms with methanol and sealing the tube, the arm containing the ligand was submerged in a $60{ }^{\circ} \mathrm{C}$ oil bath. Yellow crystals (decomposition point of $333^{\circ} \mathrm{C}$ ) were precipitated for 9 days on the other arm that was placed at room temperature. Afterwards, the crystals were filtered, rinsed in water, and dried in air with a yield of $70 \%(0.402 \mathrm{~g})$. The results obtained were as follows: $\mathrm{H}$ : $2.0 \%, \mathrm{C}: 25.5 \%$ and $\mathrm{N}: 10.0 \%$. Moreover, C: $24.9 \%, \mathrm{H}: 1.5 \%$ and $\mathrm{N}: 9.7 \%$ were obtained for $\mathrm{C}_{12} \mathrm{H}_{10} \mathrm{Br}_{2} \mathrm{~N}_{4} \mathrm{~Pb}$. The selected FTIR bands $\left(\mathrm{cm}^{-1}\right)$ were as follows: 634s, $750 \mathrm{~s}, 864 \mathrm{~m}, 1045 \mathrm{~m}$, $1418 s, 1482 m, 1590 s, 1620 s, 3024 w$.

\subsection{Preparation of Nanoparticles of $\mathrm{Pb}(\mathrm{II})$ Oxide}

After dissolving $0.1 \mathrm{mmol}$ of $\left[\mathrm{Pb}(\mathrm{L}) \mathrm{Br}_{2}\right]_{\mathrm{n}}(\mathbf{1})$ in $10 \mathrm{~mL}$ of oleic acid, the light-yellow solution obtained was degassed for forty-five minutes (with stirring and slow heating) and then heated for one hour at $180^{\circ} \mathrm{C}$, ultimately yielding a black precipitate. After adding a great amount of ethanol and a little toluene to the solution, lead(II) oxide nanoparticles were centrifuged and thereby isolated. The final solid was rinsed in ethanol and dried at room temperature (yield: $43 \%, 0.01 \mathrm{~g}$ ).

\subsection{X-ray Crystallography}

A $0.65 \times 0.15 \times 0.09 \mathrm{~mm}^{3}$ yellow compound crystal was placed over glass fiber using epoxy adhesives. An X-ray diffractometer $(50 \mathrm{kV}, 30 \mathrm{~mA})$ with graphite monochromated Mo $K_{\alpha}$ radiation $(\lambda=0.71073 \AA)$ was used over $2 \theta=4.56-50.08^{\circ}$ to collect data. No significant data were missing from the data collected. The data were processed in the crystal structure analysis module of the Bruker AXS [26]. The modules of AXS utilized included SADABS (Bruker) for absorption correction, SHELXS-97 (Sheldrick) and XPREP (Bruker) for structure solution, SHELXTL (Sheldrick) for molecular graphics and publication materials, SHELXL-97 (Sheldrick) for structure refinement, APEX2 (Bruker) for data collection, and SAINT (Bruker) for cell refinement and data reduction. Furthermore, the method proposed by Waber and Cromer was used to obtain scattering factors for neutral atoms [27]. The crystal was of the monoclinic space group $P 2_{1} / c$ given the systematic deficiency, E statistic, and effective structure refining. Furthermore, the structure was solved by utilizing direct techniques. For the data obtained from the compound, full-matrix least squares 
refinement was performed by minimizing the function of $\sum w\left(F_{c}^{2}-F_{0}^{2}\right)^{2}$. Moreover, nonhydrogen atoms were anisotropically refined. The location of the hydrogen atoms was geometrically determined with $0.98 \AA\left(\mathrm{CH}_{3}\right)$ and $\mathrm{C}-\mathrm{H}=0.95$ (aromatic) and refined with Uiso $(\mathrm{H})=-1.2 \mathrm{UeqC}$ as riding atoms. Tables 1 and 2 present the crystallographic data, the bond lengths, and the angles.

Table 1. Crystal data and structure refinement for $\left[\mathrm{Pb}(\mathrm{L}) \mathrm{Br}_{2}\right]_{\mathrm{n}}(\mathbf{1})$.

\begin{tabular}{|c|c|}
\hline Empirical Formula & $\mathrm{C}_{12} \mathrm{H}_{10} \mathrm{Br}_{2} \mathrm{~N}_{4} \mathrm{~Pb}$ \\
\hline Formula weight & 555.23 \\
\hline Temperature/K & $293(2)$ \\
\hline Crystal system & monoclinic \\
\hline Space group & $P 2_{1} / c$ \\
\hline $\mathrm{a} / \AA$ & $4.005(7)$ \\
\hline $\mathrm{b} / \AA$ & $9.169(13)$ \\
\hline$c / \AA$ & $34.27(4)$ \\
\hline$\alpha /^{\circ}$ & 90.00 \\
\hline$\beta /{ }^{\circ}$ & $92.08(4)$ \\
\hline$\gamma /{ }^{\circ}$ & 90.00 \\
\hline Volume $/ \AA^{3}$ & $1258(3)$ \\
\hline $\mathrm{Z}$ & 4 \\
\hline$\rho_{\text {calc }} \mathrm{mg} / \mathrm{mm}^{3}$ & 2.922 \\
\hline$\mu / \mathrm{mm}^{-1}$ & 19.751 \\
\hline $\mathrm{F}(000)$ & 1000.0 \\
\hline Crystal size $/ \mathrm{mm}^{3}$ & $0.65 \times 0.15 \times 0.09$ \\
\hline $2 \Theta$ range for data collection & 4.76 to $50.08^{\circ}$ \\
\hline Index ranges & $-4 \leq \mathrm{h} \leq 3,-10 \leq \mathrm{k} \leq 10,-37 \leq 1 \leq 40$ \\
\hline Reflections collected & 6637 \\
\hline Independent reflections & $1789[\mathrm{R}(\mathrm{int})=0.0834]$ \\
\hline Data/restraints/parameters & $1789 / 0 / 160$ \\
\hline Goodness-of-fit on $\mathrm{F}^{2}$ & 1.101 \\
\hline Final $R$ indexes $[\mathrm{I}>=2 \sigma(\mathrm{I})]$ & $\mathrm{R}_{1}=0.1166, \mathrm{w} \mathrm{R}_{2}=0.2949$ \\
\hline Final $\mathrm{R}$ indexes (all data) & $\mathrm{R}_{1}=0.1255, \mathrm{wR}_{2}=0.3013$ \\
\hline Largest diff. peak/hole/e $\AA^{-3}$ & $5.58 /-3.65$ \\
\hline
\end{tabular}

Table 2. Selected bond lengths $(\AA)$ and angles $\left(^{\circ}\right)$ for $\left[\mathrm{Pb}(\mathrm{L}) \mathrm{Br}_{2}\right]_{n}(\mathbf{1})$.

\begin{tabular}{|c|c|c|c|}
\hline $\mathrm{Pb} 1-\mathrm{N} 2$ & $2.67(2)$ & $\mathrm{Pb} 1-\mathrm{Br} 1$ & $2.992(4)$ \\
\hline $\mathrm{Pb} 1-\mathrm{N} 2{ }^{\mathrm{i}}$ & $2.67(2)$ & $\mathrm{Pb} 1-\mathrm{Br} 1$ iii & $2.975(4)$ \\
\hline $\mathrm{Pb} 1-\mathrm{Br} 1 \mathrm{ii}$ & $2.975(4)$ & $\mathrm{Pb} 1-\mathrm{Br} 1^{\mathrm{i}}$ & $2.992(4)$ \\
\hline $\mathrm{N} 2-\mathrm{Pb} 1-\mathrm{N} 2{ }^{\mathrm{i}}$ & $180.000(12)$ & $\mathrm{N} 2-\mathrm{Pb} 1-\mathrm{Br} 1 \mathrm{ii}$ & $91.2(6)$ \\
\hline $\mathrm{N} 2-\mathrm{Pb} 1-\mathrm{Br} 1$ & $84.4(5)$ & 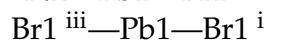 & $84.32(13)$ \\
\hline $\mathrm{N} 2^{\mathrm{i}}-\mathrm{Pb} 1-\mathrm{Br} 1$ & $95.6(5)$ & $\mathrm{Br} 1^{\mathrm{ii}}-\mathrm{Pb} 1-\mathrm{Br} 1^{\mathrm{i}}$ & $95.68(13)$ \\
\hline $\mathrm{N} 2^{\mathrm{i}}-\mathrm{Pb} 1-\mathrm{Br} 1^{\mathrm{iii}}$ & $91.2(6)$ & $\mathrm{Br} 1{ }^{\mathrm{iii}}-\mathrm{Pb} 1-\mathrm{Br} 1$ & $95.68(13)$ \\
\hline $\mathrm{N} 2-\mathrm{Pb} 1-\mathrm{Br} 1 \mathrm{iii}$ & $88.8(6)$ & $\mathrm{Br} 1$ ii $-\mathrm{Pb} 1-\mathrm{Br} 1$ & $84.32(13)$ \\
\hline $\mathrm{N} 2-\mathrm{Pb} 1-\mathrm{Br} 1^{\mathrm{i}}$ & $95.6(5)$ & $\mathrm{Br} 1{ }^{\mathrm{i}}-\mathrm{Pb} 1-\mathrm{Br} 1$ & $180.00(9)$ \\
\hline $\mathrm{N} 2^{\mathrm{i}}-\mathrm{Pb} 1-\mathrm{Br} 1^{\mathrm{i}}$ & $84.4(5)$ & 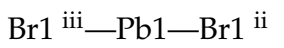 & $180.00(9)$ \\
\hline $\mathrm{N} 2^{\mathrm{i}}-\mathrm{Pb} 1-\mathrm{Br} 1^{\mathrm{ii}}$ & $88.8(6)$ & & \\
\hline
\end{tabular}

\section{Results and Discussion}

$\left[\mathrm{Pb}(\mathrm{L}) \mathrm{Br}_{2}\right]_{\mathrm{n}}(\mathbf{1})$ was obtained as a novel one-dimensional fishbone coordination polymer from the reaction of lead(II) bromide with 1,2-bis (pyridine-3-ylmethylene)hydrazine (L). The nanostructure of the compound was determined in an aqueous solution through UST irradiation. The suitable single crystals of compound I for X-ray crystallography were obtained using the heat gradient of an aqueous solution based on the branched-tube method [28]. 
According to Figure 1, the bulk material developed using the branched-tube approach could not be differentiated from the nanostructured material obtained using the sonochemical approach in terms of FTIR spectrum and the results of elemental analysis. The FTIR spectrum of the single crystal materials and nanostructured material showed the representative absorption bands of the " $\mathrm{L}$ " ligand. Furthermore, the aromatic $\mathrm{C}-\mathrm{H}$ absorption of hydrogen atoms caused a relatively weak band at approximately $3021 \mathrm{~cm}^{-1}$. The aromatic ring vibration of the "L" ligand was also observed at frequencies of $1418-1590 \mathrm{~cm}^{-1}$.

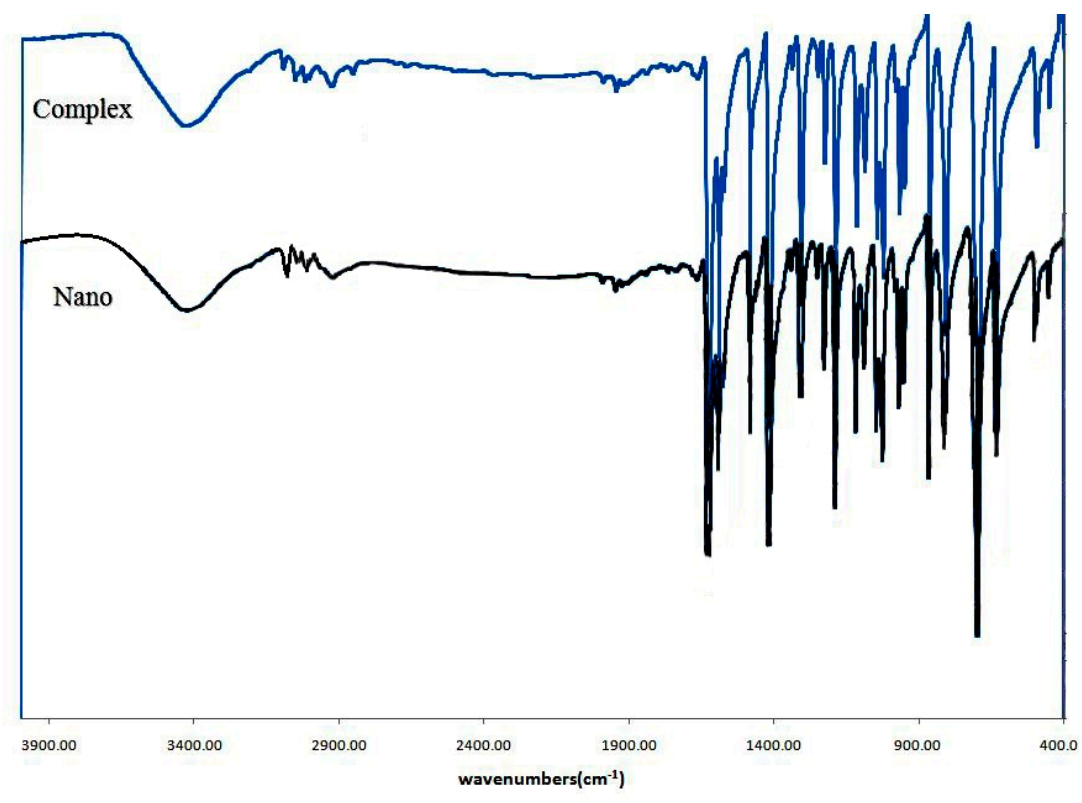

Figure 1. FT-IR spectrum of crystal and nano structure of $\mathbf{1}$.

Tables 1 and 2 show the results of single-crystal XRD for the structure of compound I. According to the single-crystal XRD in Figure 2, the structure of $\left[\mathrm{Pb}(\mathrm{L}) \mathrm{Br}_{2}\right]_{n}$ crystallized in a monoclinic system with the space group of $\mathrm{P} 2_{1} / \mathrm{c}$ resembled that of solid $1 \mathrm{D}$ fishbone metal-organic coordination polymers. Figure $2 \mathrm{a}$ shows the structure of the asymmetrical unit of $\mathbf{1}$ and an atom numbering arrangement selected. $\mathrm{A} \mathrm{Pb}$ atom is coordinated by two $\mathrm{N}$ atoms of the $L$ ligand with the same $\mathrm{Pb}-\mathrm{N}$ distance of $2.670 \AA$ and four bridged bromine anions with a Pb-Br distance of $2.992(2.972,2.992$ and $2.972 \AA$ ). Figure $2 b$ shows a coordination number of six for lead(II) atom in two modes with a $\mathrm{PbN}_{2} \mathrm{Br}_{4}$ donor set. The adjusted $\mathrm{Pb} \cdots \mathrm{Pb}$ distances belonging to the chain were $4.001 \AA$. This order demonstrates a symmetry in the coordination geometry surrounding metal ions in a holodirected fashion. Given the labile interactions, the architecture of one-dimensional chains was allowed to interact with neighboring chains, and the structure was also allowed to be extended into three-dimensional supramolecular metal-organic coordination polymers, as shown in Figure 2d. 
(a)

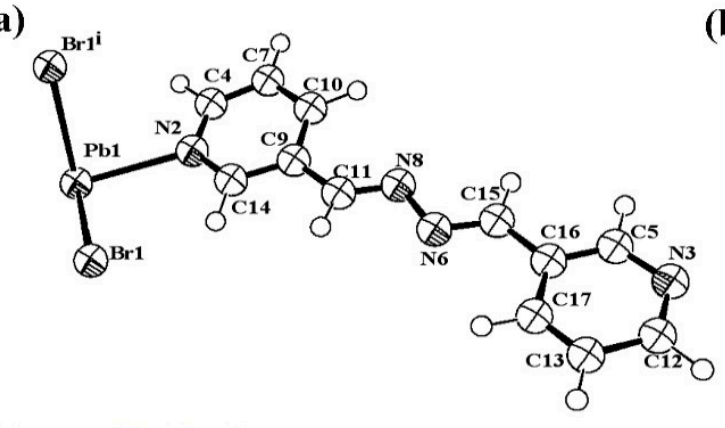

(b)

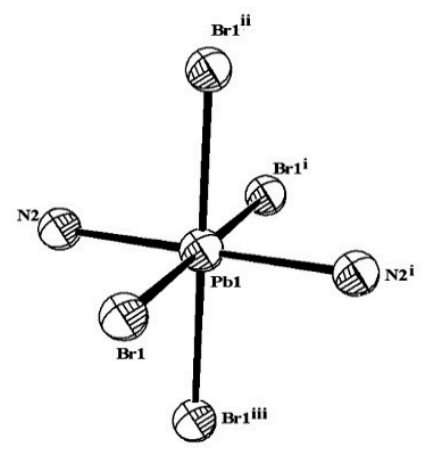

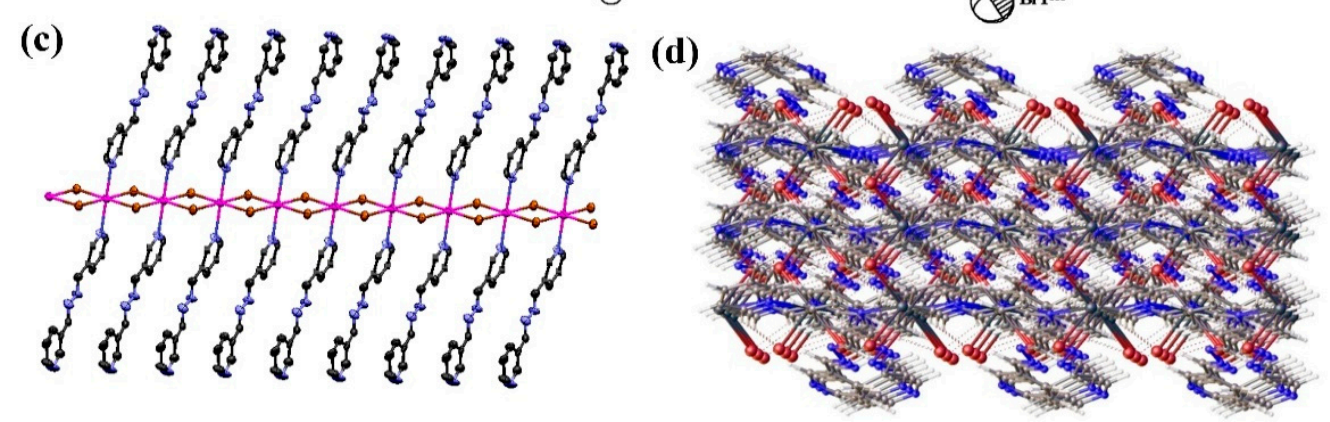

Figure 2. (a) Molecular structure of asymmetrical unit (1). (b) Coordination sphere of $\mathrm{Pb}$ (II) in 1. (c) Fragment of the coordination polymer showing the 1D fish bone metal-organic coordination polymer. (d) From 1D architecture to supramolecular 3D coordination polymer via labile interactions (such as aromatic and $\pi-\pi$ interaction, $\mathrm{H}$-bonding).

Figure 3a shows the XRD pattern of compound 1 simulated from the single-crystal $\mathrm{X}$-ray data, and Figure $3 \mathrm{~b}$ shows the experimental XRD pattern of compound $\mathbf{1}$ prepared by using the sonochemical process. Except for slight changes in $2 \theta$, the experimental data were consistent with the simulated XRD patterns, suggesting that the compound obtained as a nano-structure using the sonochemical method was the same as that derived through single-crystal XRD. The major peak enlargmenet showed the nano-dimension of the particles. According to $D=0.891 \lambda / \beta \cos \theta$ as the Scherrer equation, the mean size of the grain was estimated at $39 \mathrm{~nm}$, with $D$ representing the mean grain size, $\lambda=0.15405 \mathrm{~nm}$ as the $\mathrm{X}$-ray wavelength, and $\theta$ and $\beta$ as the diffraction and full-width angles, respectively, at $50 \%$ of a peak.

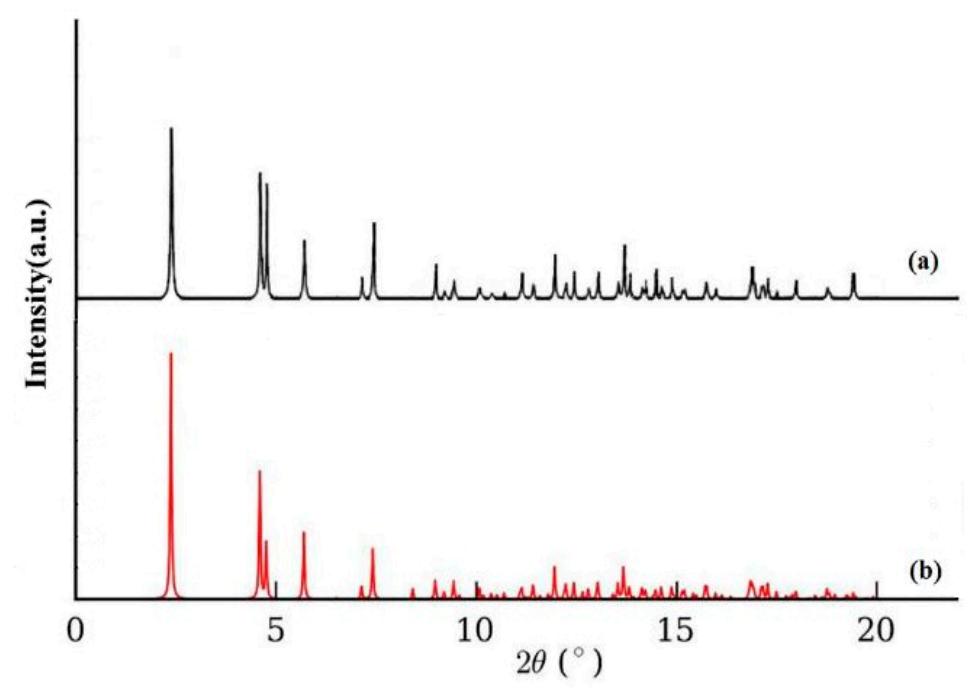

Figure 3. X-ray Powder Diffraction Pattern (XRPD) of compound 1 (a) computed from single-crystal $X$-ray data and (b) from the nanorods. 
The crystalline substance was provided with $\left[\mathrm{Pb}(\mathrm{L}) \mathrm{Br}_{2}\right]_{\mathrm{n}}(\mathbf{1})$ through the reaction of 1,2-bis (pyridin-3-ylmethylene)hydrazine (L) with lead(II) bromide. In addition, the size and morphology of compound I prepared by the UST technique were analyzed with SEM. Figure 4 shows the SEM of compound I acquired by using a $600 \mathrm{~W}$ ultrasonic generator at $a\left[\mathrm{~Pb}^{2+}\right]=\left[\mathrm{L}^{-}\right]=0.1 \mathrm{M}$ concentration of primary reagents. Figure 4 also shows the nanorod morphology with a diameter of 45-140 nm for compound I. Further assessments are required for clarifying the formation of these structures. Packing the system at molecular levels, however, morphologically affects the nanostructured compound, suggesting coordination-encouraged creation over the morphology of the nanostructure [29-32].

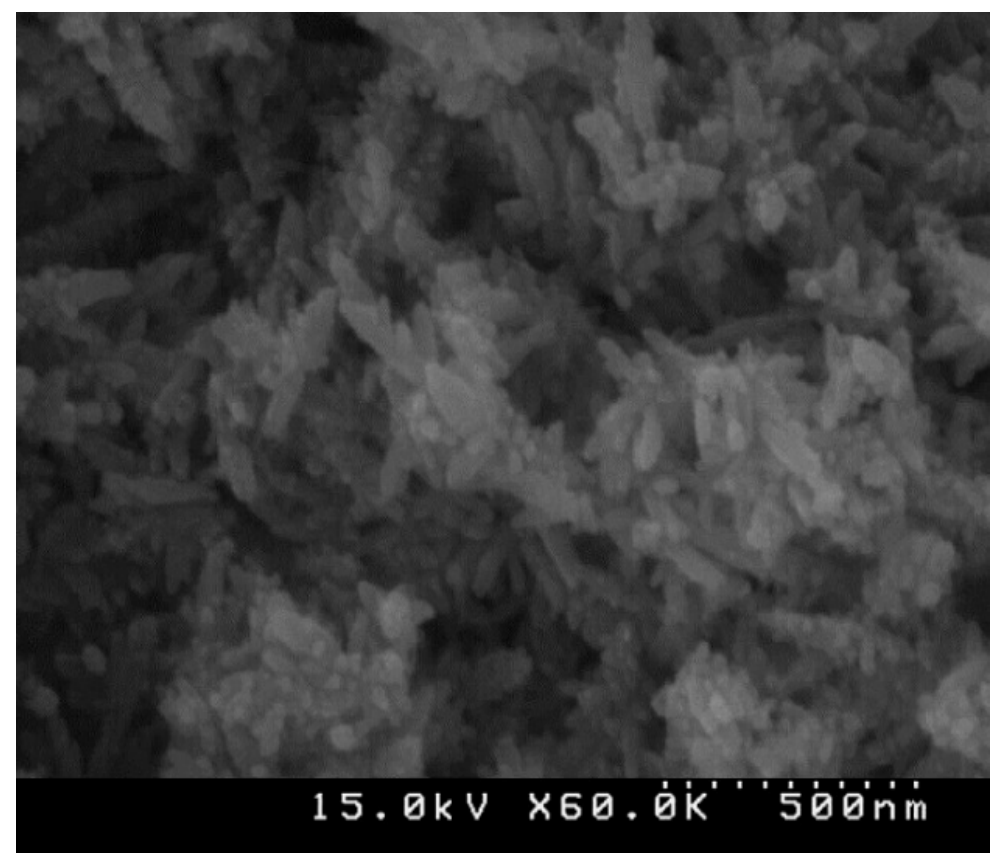

Figure 4. SEM photographs of $\left[\mathrm{Pb}(\mathrm{L}) \mathrm{Br}_{2}\right]_{\mathrm{n}}(\mathbf{1})$ nanorods.

Figure 5 shows the results of the TGA of the single crystals and nanostructures performed at $25-600{ }^{\circ} \mathrm{C}$ in argon to investigate the thermal stability of compound 1 . For single crystals of $\left[\mathrm{Pb}(\mathrm{L}) \mathrm{Br}_{2}\right]_{n}$, after removing water molecules from the coordinated molecules and moisture at $80-110{ }^{\circ} \mathrm{C}$, compound 1 was stable at up to $160{ }^{\circ} \mathrm{C}$. Decomposition at $160-425{ }^{\circ} \mathrm{C}$ resulted in a mass loss of about $47.8 \%$. In the case of nanostructured $\left[\mathrm{Pb}(\mathrm{L}) \mathrm{Br}_{2}\right]_{\mathrm{n}}$, the decomposition started at a lower temperature, around $145^{\circ} \mathrm{C}$, with the similar weight loss. This may be attributed to different crystallographic surfaces of both samples exposed to a thermal gradient [33]. The thermal stability of $\left[\mathrm{Pb}(\mathrm{L}) \mathrm{Br}_{2}\right]_{\mathrm{n}}$ is much lower than our previous reports on lead (II) coordination polymer, which may be attributable to differences in the structures of ligands coordinated to lead [34,35]. XPS findings showed that the solid residue at about $600{ }^{\circ} \mathrm{C}$ was $\mathrm{PbO}$. 


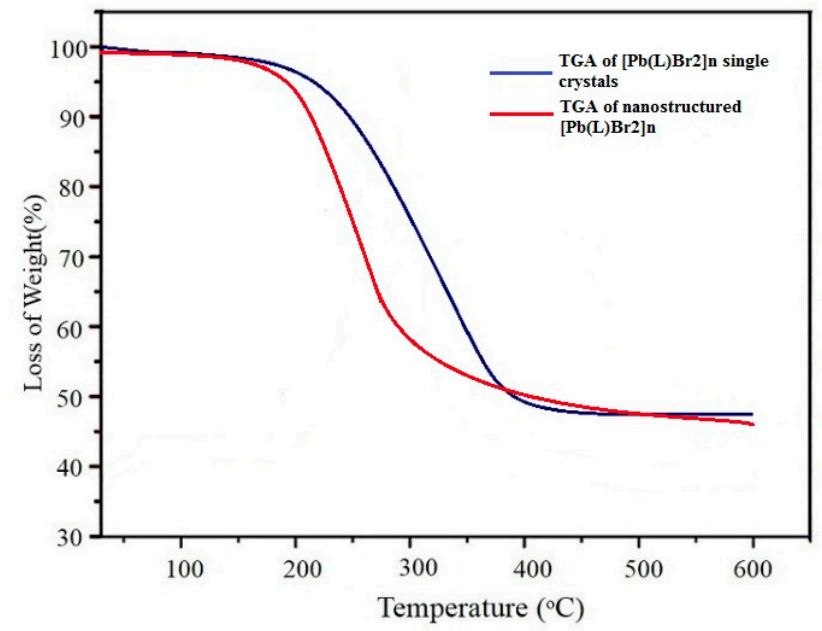

Figure 5. TGA plot of $\left[\mathrm{Pb}(\mathrm{L}) \mathrm{Br}_{2}\right]_{\mathrm{n}}(\mathbf{1})$ in single crystal shape and nanostructured mode.

The final products of the decomposition of compound 1 based on their XRD arrangements as per Figure $6 \mathrm{a}$ matched the standard design of tetragonal $\mathrm{PbO}$ with S.G $=\mathrm{P} 4 / \mathrm{nmm}$, $\mathrm{a}=3.947 \AA, \mathrm{Z}=2, \mathrm{c}=4.988 \AA$ and JCPDS (Joint Committee on Powder Diffraction Standards) card file No: 85-0711. Figure $6 \mathrm{~b}$ displays the XPS results of nano PbO. The two asymmetric peaks at $142.28 \mathrm{eV}$ and $137.48 \mathrm{eV}$ were attributed to the transitions of $4 \mathrm{f}_{5 / 2}$ and $4 f_{7 / 2}$ from $\mathrm{Pb}^{2+}$ ions in $\mathrm{PbO}$, respectively, indicating that $\mathrm{Pb}^{2+}$ in the product was the same as $\mathrm{PbO}$ in shape. The $\mathrm{O} 1 \mathrm{~s}$ spectrum showed a peak at $531.1 \mathrm{eV}$, which was estimated at $530.9 \mathrm{eV}$ of $\mathrm{O} 1 \mathrm{~s}$ in $\mathrm{PbO}$ in the literature. Figure 7 shows the SEM and TEM results of the residue obtained from the thermolysis of 1 at $180{ }^{\circ} \mathrm{C}$ by employing oleic acid as a surfactant, suggesting the regular shape of $\mathrm{Pb}(\mathrm{II})$ oxide nanoparticles. The significant broadening of the peaks indicates that the particles have nanometer dimensions. The average grain size $\mathrm{D}$ was estimated as $58 \mathrm{~nm}$ using the Scherrer formula, $D=0.891 \lambda / \beta \cos \theta$, where $\lambda$ is the $X$-ray wavelength $(0.15405 \mathrm{~nm})$ and $\theta$ and $\beta$ are the diffraction angle and full-width at half maximum of an observed peak, respectively [36].

a
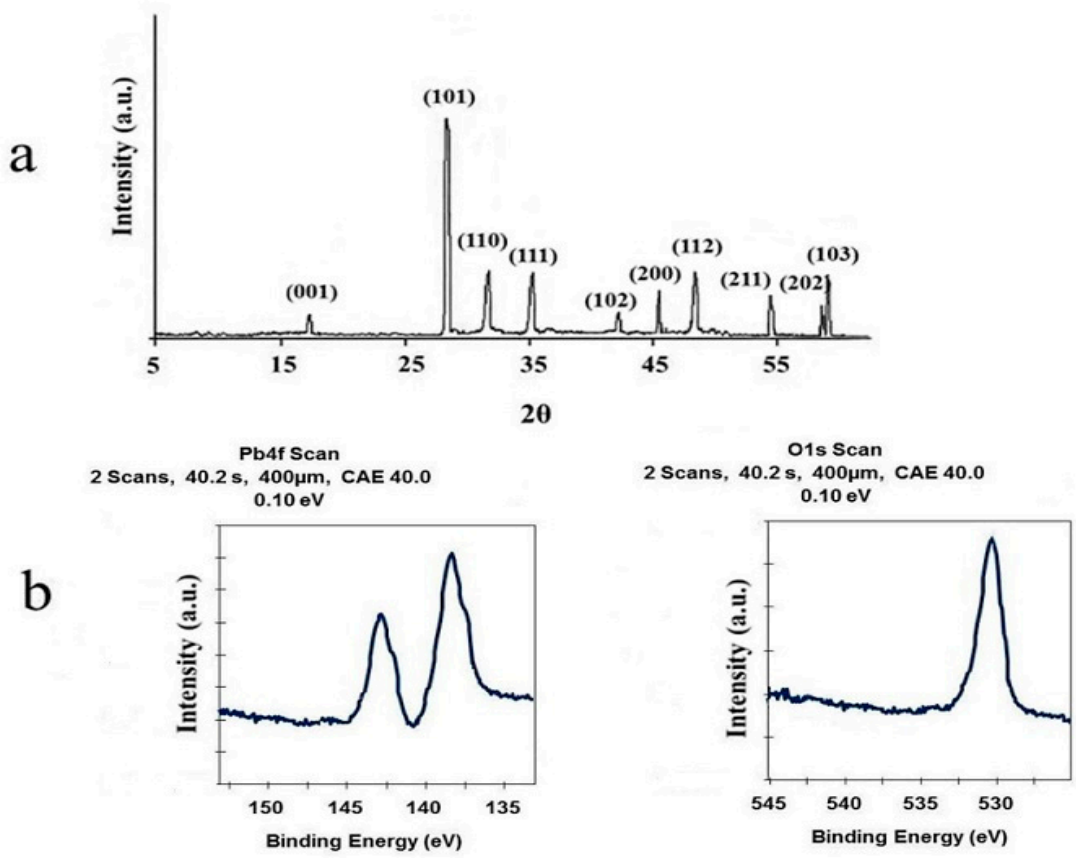

Figure 6. (a) XRD pattern and (b) XPS spectra of PbO nanoparticles prepared by thermolysis of compound 1. 

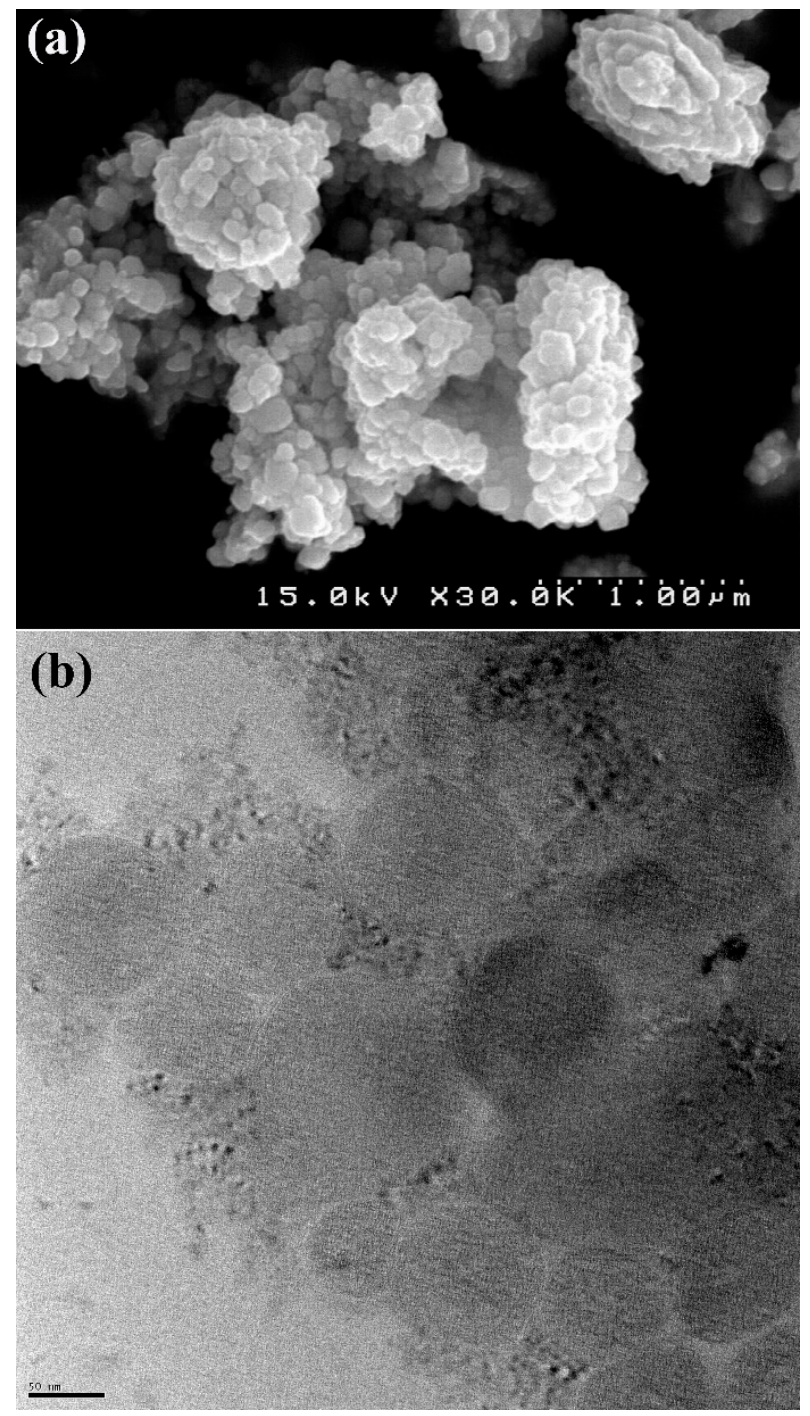

Figure 7. (a) SEM and (b) TEM images of PbO nano-structures produced by the thermolysis of nano-structures of compound 1.

\section{Conclusions}

In this study, a sonochemical method was used to synthesize nano-structures of a new 1D fishbone coordination polymer of divalent lead with 1,2-bis (pyridin-3-ylmethylene)hydrazine (L). Single-crystal XRD was performed to structurally determine compound 1. A three-dimensional supramolecular compound included in the crystal structure of compound I demonstrated a coordination number of six in lead (II) ions. The complex takes the form of a 1D metal-organic system in solid state. As a result of several labile interactions with neighboring chains, the $1 \mathrm{D}$ chain extended into a 3D supramolecular coordination polymer. The sonochemically made compound $\mathbf{1}$ had nanorod morphology with diameter of 38-43 nm. Moreover, the calcination of compound I through the thermolysis of 1 at $180^{\circ} \mathrm{C}$ by using oleic acid as a surfactant yielded a uniform $\mathrm{PbO}$ nanoparticle.

Author Contributions: Y.H., supervision, writing—review and editing; B.M., writing—review and editing; S.W.J., project administration and editing; M.S.-R., writing—original draft preparation; M.A., formal analysis. All authors have read and agreed to the published version of the manuscript.

Funding: This work was funded by the grant NRF-2019R1A5A8080290 of the National Research Foundation of Korea.

Institutional Review Board Statement: Not applicable. 


\section{Informed Consent Statement: Not applicable.}

Data Availability Statement: Cambridge Crystallographic Data Centre provided the crystallographic information for the structures as supplementary publication CCDC-1567103 for $\left[\mathrm{Pb}\left(\mathrm{L}_{)} \mathrm{Br}_{2}\right]_{\mathrm{n}}\right.$ (1). Duplicates of these data may be acquired by contacting deposit@ccdc.cam.ac.uk by email or through official correspondence with CCDC, 12 Union Road, Cambridge CB2 1EZ, United Kingdom, Fax: +441223336033 .

Acknowledgments: The authors thank Sayyed Jamaledin Asadabadi University and Qom University for their support.

Conflicts of Interest: The authors declare no conflict of interest.

\section{References}

1. Chakrabarty, R.; Mukherjee, P.S.; Stang, P.J. Supramolecular coordination: Self-assembly of finite two-and three-dimensional ensembles. Chem. Rev. 2011, 111, 6810-6918. [CrossRef]

2. Hu, M.L.; Morsali, A.; Aboutorabi, L. Lead (II) carboxylate supramolecular compounds: Coordination modes, structures and nano-structures aspects. Coord. Chem. Rev. 2011, 255, 2821-2859. [CrossRef]

3. Leong, W.L.; Vittal, J.J. One-dimensional coordination polymers: Complexity and diversity in structures, properties, and applications. Chem. Rev. 2011, 111, 688-764. [CrossRef] [PubMed]

4. Akhbari, K.; Morsali, A. Thallium (I) supramolecular compounds: Structural and properties consideration. Coord. Chem. Rev. 2010, 254, 1977-2006. [CrossRef]

5. Gharib, M.; Safarifard, V.; Morsali, A. Ultrasound assisted synthesis of amide functionalized metal-organic framework for nitroaromatic sensing. Ultrason. Sonochem. 2018, 42, 112-118. [CrossRef] [PubMed]

6. Robin, A.Y.; Fromm, K.M. Coordination polymer networks with O-and N-donors: What they are, why and how they are made. Coord. Chem. Rev. 2006, 250, 2127-2157. [CrossRef]

7. Kitagawa, S.; Kitaura, R.; Noro, S. Functional porous coordination polymers. Angew. Chem. Int. Ed. 2004, 43, 2334-2375. [CrossRef] [PubMed]

8. Tanhaei, M.; Mahjoub, A.R.; Safarifard, V. Sonochemical synthesis of amide-functionalized metal-organic framework/graphene oxide nanocomposite for the adsorption of methylene blue from aqueous solution. Ultrason. Sonochem. 2018, 41, 189-195. [CrossRef] [PubMed]

9. Uemura, T.; Kitagawa, S. Nanocrystals of coordination polymers. Chem. Lett. 2005, 34, 132-137. [CrossRef]

10. Shimoni-Livny, L.; Glusker, J.P.; Bock, C.W. Lone pair functionality in divalent lead compounds. Inorg. Chem. 1998, $37,1853-1867$. [CrossRef]

11. Engelhardt, L.M.; Furphy, B.M.; Harrowfield, J.M.; Patrick, J.M.; White, A.H. 1: 1 Adducts of lead (II) thiocyanate with 1, 10-phenanthroline and 2, $2^{\prime}, 6^{\prime}, 2^{\prime \prime}$-terpyridine. Inorg. Chem. 1989, 28, 1410-1413. [CrossRef]

12. Akhbari, K.; Morsali, A.; Retailleau, P. Effect of two sonochemical procedures on achieving to different morphologies of lead (II) coordination polymer nano-structures. Ultrason. Sonochem. 2013, 20, 1428-1435. [CrossRef] [PubMed]

13. Platas-Iglesias, C.; Esteban-Gómez, D.; Enríquez-Pérez, T.; Avecilla, F.; de Blas, A.; Rodriguez-Blas, T. Lead (II) thiocyanate complexes with bibracchial lariat ethers: An X-ray and DFT study. Inorg. Chem. 2005, 44, 2224-2233. [CrossRef] [PubMed]

14. Taheri, S.; Mojidov, A.; Morsali, A. Two-dimensional Holodirected Lead (II) Coordination Polymer, [Pb ( $\mu$-bpp) $(\mu-S C N) 2] n$ (bpp=1, 3-di (4-pyridyl) propane). Z. Anorg. Allg. Chem. 2007, 633, 1949-1951. [CrossRef]

15. Gedanken, A. Using sonochemistry for the fabrication of nanomaterials. Ultrason. Sonochem. 2004, 11, 47-55. [CrossRef] [PubMed]

16. Bang, J.H.; Suslick, K.S. Applications of ultrasound to the synthesis of nanostructured materials. Adv. Mater. 2010, 22, 1039-1059. [CrossRef] [PubMed]

17. Son, W.J.; Kim, J.; Kim, J.; Ahn, W.S. Sonochemical synthesis of MOF-5. Chem. Commun. 2008, 47, 6336-6338. [CrossRef] [PubMed]

18. Suslick, K.S. The sonochemical hot spot. J. Acoust. Soc. Am. 1991, 89, 1885-1886. [CrossRef]

19. Safarifard, V.; Morsali, A. Facile preparation of nanocubes zinc-based metal-organic framework by an ultrasound-assisted synthesis method; precursor for the fabrication of zinc oxide octahedral nanostructures. Ultrason. Sonochem. 2018, 40, 921-928. [CrossRef] [PubMed]

20. Kojima, Y.; Koda, S.; Nomura, H. Effects of sample volume and frequency on ultrasonic power in solutions on sonication. Jpn. J. Appl. Phys. 1998, 37, 2992. [CrossRef]

21. Koda, S.; Kimura, T.; Kondo, T.; Mitome, H. A standard method to calibrate sonochemical efficiency of an individual reaction system. Ultrason. Sonochem. 2003, 10, 149-156. [CrossRef]

22. Cravotto, G.; Boffa, L.; Mantegna, S.; Perego, P.; Avogadro, M.; Cintas, P. Improved extraction of vegetable oils under high-intensity ultrasound and/or microwaves. Ultrason. Sonochem. 2008, 15, 898-902. [CrossRef] [PubMed]

23. Safarifard, V.; Morsali, A. Applications of ultrasound to the synthesis of nanoscale metal-organic coordination polymers. Coord. Chem. Rev. 2015, 292, 1-14. [CrossRef]

24. Mercury 1.4.1; Copyright Cambridge Crystallographic Data Centre: Cambridge, UK, 2001-2005. 
25. Harrowfield, J.M.; Miyamae, H.; Skelton, B.W.; Soudi, A.A.; White, A.H. Lewis-base adducts of lead (II) compounds. XX. synthesis and structure of the 1: 1 adduct of pyridine with lead (II) thiocyanate. Aust. J. Chem. 1996, 49, 1165-1169. [CrossRef]

26. SHELXTL, N.T. Crystal Structure Analysis Package, Version 6.14; Bruker AXS: Madison, WI, USA, 2000.

27. Cromer, D.T.; Waber, J.T. International Tables for X-ray Crystallography; Table 2.2 A; Kynoch Press: Birmingham, UK, $1974 ;$ Volume 4.

28. Morsali, A.; Masoomi, M.Y. Structures and properties of mercury (II) coordination polymers. Coord. Chem. Rev. 2009, 253, 1882-1905. [CrossRef]

29. Fard, M.J.S.; Morsali, A. Sonochemical Synthesis of New Nano-Belt One-Dimensional Double-Chain Lead (II) Coordination Polymer; As Precursor for Preparation of $\mathrm{PbBr}(\mathrm{OH})$ Nano-Structure. J. Inorg. Organomet. Polym. Mater. 2010, $20,727-732$. [CrossRef]

30. Ranjbar, Z.R.; Morsali, A.; Retailleau, P. Thermolysis preparation of zinc (II) oxide nanoparticles from a new micro-rods onedimensional zinc (II) coordination polymer synthesized by ultrasonic method. Inorg. Chim. Acta 2011, 376, 486-491. [CrossRef]

31. Ranjbar, Z.R.; Morsali, A. Preparation of Zinc (II) Oxide Nanoparticles from a New Nano-Size Coordination Polymer Constructed from a Polypyridyl Amidic Ligand; Spectroscopic, Photoluminescence and Thermal Analysis Studies. J. Inorg. Organomet. Polym. Mater. 2011, 21, 421-430. [CrossRef]

32. Masoomi, M.Y.; Mahmoudi, G.; Morsali, A. Sonochemical syntheses and characterization of new nanorod crystals of mercury (II) metal-organic polymer generated from polyimine ligands. J. Coord. Chem. 2010, 63, 1186-1193. [CrossRef]

33. Marzbanrad, E.; Rivers, G.; Peng, P.; Zhao, B.; Zhou, N.Y. How morphology and surface crystal texture affect thermal stability of a metallic nanoparticle: The case of silver nanobelts and pentagonal silver nanowires. Phys. Chem. Chem. Phys. 2015, 17, 315-324. [CrossRef] [PubMed]

34. Hanifehpour, Y.; Mirtamizdoust, B.; Ahmadi, H.; Wang, R.; Joo, S.W. Ultrasonic-assisted synthesis, characterizing the structure and DFT calculation of a new $\mathrm{Pb}(\mathrm{II})$-chloride metal-ligand coordination polymer as a precursor for preparation of $\alpha-\mathrm{PbO}$ nanoparticles. J. Mol. Struct. 2021, 1124, 129031. [CrossRef]

35. Hanifehpour, Y.; Mirtamizdoust, B.; Ahmadi, H.; Wang, R.; Joo, S.W. Sonochemical synthesis, crystal structure, and DFT calculation of an innovative nanosized $\mathrm{Pb}(\mathrm{II})$-azido metal-organic coordination polymer as a precursor for preparation of $\mathrm{PbO}$ nanorod. Chem. Pap. 2020, 74, 3651-3660. [CrossRef]

36. Patterson, A.L. The Scherrer formula for X-ray particle size determination. Phys. Rev. 1939, 56, 978. [CrossRef] 